\title{
Understanding efficiencies behind logistics service providers' green offerings
}

\author{
Karin Isaksson and Maria Huge-Brodin
}

\section{Linköping University Post Print}

\section{Tweet}

N.B.: When citing this work, cite the original article.

Original Publication:

Karin Isaksson and Maria Huge-Brodin, Understanding efficiencies behind logistics service providers' green offerings, 2013, Management Research Review, (36), 3, 216-238.

http://dx.doi.org/10.1108/01409171311306382

Copyright: Emerald

http://www.emeraldinsight.com/

Postprint available at: Linköping University Electronic Press

http://urn.kb.se/resolve?urn=urn:nbn:se:liu:diva-73990 


\title{
UNDERSTANDING EFFICIENCIES BEHIND LOGISTICS SERVICE PROVIDERS' GREEN OFFERINGS
}

\begin{abstract}
Purpose - Awareness of environmental impacts on our society is increasing among companies. In order to turn environmental problems into business opportunities, many companies are beginning to consider how environmental, or green aspects can be integrated into their service offerings. This opportunity can be of specific interest to logistics service providers, whose core business is an environmental impact in itself. The purpose of this article is to indicate where green-labelled logistics service providers are positioned today in their development, and to seek the underlying rationale in development of green service offerings.
\end{abstract}

Design/methodology/approach - This article takes a logistics service provider's perspective and is based on a multiple case study of 6 companies. The analysis is based on cross-case analysis, and empirical, as well as theoretical, pattern matching.

Findings - The attitude towards a green approach differs among the case companies: while some are working towards a green integration throughout the entire business, others offer green alternatives to the original service offering. The results point to possible explanations for these differences, and include differences in range of service offerings, size, and to different management principles for green aspects.

Practical implications - This article can inspire logistics service providers in their continuing work to integrate green initiatives into the company. By introducing alternative green approaches in the development of service offerings, logistics service providers can match their own business and context with alternative rationales.

Originality/value - While most of the green logistics research focuses on the logistics system's characteristics, this article offers initial insights into how the integration of green aspects into logistics services can impact logistics service providers.

Keywords: Green logistics service offering, logistics service providers, new service development, efficiencies, multiple case study, pattern matching.

Paper Research paper

\section{Introduction}

The pace of change is increasing and impacting the conditions of the logistics and transport market. From a traditional point of view, the transport function is often regarded to be separate from the rest of the supply chain and has a focus on cost minimisation (Stank and Goldsby, 2000). However, this traditional view of transport is challenged by the recognition that transport has the potential to play a positive value-adding role in supply chains (Bø and Hammervoll, 2010) and also by the emerging demand for advanced logistics services (Hertz and Alfredsson, 2003; Evangelista and Sweeney, 2006). This shift in perspective can be explained by globalization trends, demands for lead time reductions, customer orientation (Peters et al., 1998), outsourcing (Wolf and Seuring, 2010) and increased technology use (Evangelista and Sweeney, 2006). In general, a transport system has to be flexible and efficient to be able to respond to constant fluctuations in services, volumes, types and to the types of destination of freight flows (Sheffi, 1990). However, Berglund et al., (1999) highlight 
the importance of an increased focus on customers, IT-systems and skills when logistics service providers gradually realize and start acting upon these fluctuations and changes, something which often leads to a widening of the range of services.

Since the beginning of the twenty-first century, the practice of responding to environmental, or green concerns in a socially responsible manner, has become an important business issue (Murphy and Poist, 2003). This change has led to a situation that can be described by citing Berns et al. (2009); "Companies have to start to think more broadly and proactively about sustainability's potential impact on their business and industry - and begin to plan and act" (p. 26). There is no doubt that there is an increased awareness of the environmental impact in society. This has resulted in government regulations and changing consumer demands, which in turn, have led to increased pressures on companies in general.

The transport- and logistics industry is especially vulnerable to this development. Transports play a critical role in the supply chain (Potter and Lalwani, 2008) and have attracted attention in recent years because of their negative environmental impact. In order to turn environmental problems into business opportunities, logistics service providers must work towards establishing and adopting green logistics initiatives. The importance of green management has increased dramatically over the past decade (compare e.g. Skjoett-Larsen, 2000 and McKinnon, 2010), and in order to deliver products and services to customers in more environmentally friendly ways, logistics service providers need to improve their green performance (Murphy and Poist, 2003). Green management and integrating green issues into logistics service offerings has involved more and more LSPs and will probably attract even more managerial attention in the logistics industry in the future (Lieb and Lieb, 2010). Research into the type and content of logistics services has previously divided logistics services into transports, warehousing, inventory, value-added services, information services and the design and reengineering of the supply chain (Andersson, 1997; Berglund, 2000). Although logistics service providers are becoming aware of environmental problems and are turning greener (e.g. Erhardt, 2010; DB Scenker, 2011), the integration of green thinking into logistics service offerings is still at an early stage. An offering can be regarded as having two elemental characteristics: its value to the customer and its price (Anderson et al., 2000). To integrate environmental thinking into the service offerings and quantify its added value will be a challenge for logistic service providers, and it is clear that there is a lack of knowledge and research in this area.

This article takes a logistics service provider's perspective, and its purpose is to indicate where green-labelled logistics service providers are positioned today in their development of green service offerings. The article also seeks to explain the underlying rationales behind the development of green service offerings.

Following this introduction, the development and the content of logistics service offerings is presented, this is done partly from a green perspective and is framed by service literature. This is followed by a brief overview of the theoretical starting points for analysing the underlying rationale for developing green service offerings. Thereafter, the research method that we have used to examine the development of green service offerings within the logistics industry is described. This is followed by an overall presentation of the case companies. The two-step analysis includes an analysis of the present state of green service offerings, and a pattern-matching analysis to explore the differences indicated in the first step. The concluding section discusses the main findings and the research and managerial implications. 


\section{Development of new and green logistics services}

For more than two decades now academic interest and research has been giving increased attention to the logistics service industry (Maloni and Carter, 2006). The development of logistics service providers (LSPs) has been growing in scope and complexity, and new players have entered the market. Berglund (2000) identifies three distinct waves of entrants into the third-party logistics (TPL) industry over the last two decades of the $20^{\text {th }}$ century: "traditional" LSPs (companies originating in transport, forwarding and warehousing); network players (providing efficient transportation and warehousing but with a higher IT capability); and the third wave, where new entrants from other areas, such as information technology, management consultancy and even the financial sector, cooperate with players from the first and second waves. For example, the recent development of the logistics service industry has seen an increased focus on the management of customer relationships and services (Hertz and Alfredsson, 2003) and third- and fourth party arrangements and alliances (Bask et al., 2010). Strong and flexible inter-firm relationships which facilitate organisational learning and innovation can improve the LSPs' supply chain efficiency and supply chain performance (Panayides and So, 2005). Hertz and Alfredsson (2003) highlight the importance of developing skills, competences and the creation of specific knowledge for adding customer value.

In this evolving process, the logistics service industry could have a more value-added role by providing "green" logistics, which in turn allows their customers to produce even "greener" products and services for end-customers (Wu and Dunn, 1995). This requires that LSPs provide their customers with green services, something which can be compared to a new service offering. In order to provide a wide view of a new service offering and its components, we start from the six dimensions of a service innovation suggested by den Hertog et al. (2010), presented below. Since there is a lack of literature on logistics service offerings connected to environmental issues (Isaksson and Björklund, 2010), we broaden the scope of the literature to embrace logistics service offerings in general.

\section{N1 New service concept or service offering}

A new service concept is often a new way of thinking about how to organize a solution to a problem or the need of a customer, and consists of new combinations or configurations of services that do exist either individually or as parts of other services (den Hertog et al., 2010). The content of logistics services has been studied by a number of researchers (e.g. Berglund, 2000, Hertz and Alfredsson, 2003, Peters et al, 1998) but much of the literature appears to focus on the demand-side of logistics services (Selviaridis and Spring, 2007). Generally, logistics services range from basic logistics, like freight forwarding, courier, express and postal services, to the provision of complex service bundles and logistics solutions. The expansion of logistics services can be explained by the need for more professional and betterequipped logistics services and with the cost savings that these can provide (Sheffi, 1990) and also by the varying and different logistics needs of different kinds of companies (Hertz and Alfredsson, 2003).

Peters et al. (1998) emphasise the importance for LSPs to develop value-added services to strengthen and broaden their offering range. In the narrow literature about the adoption of environmental considerations in logistics service offerings, Isaksson and Björklund (2010) propose a framework that considers green aspects in the development of logistics service offerings. Further, Martinsen and Huge-Brodin (2010) suggest nine green categories to be included in an environmental logistics service offering. The categories consist of fuel alternatives, environmentally classified vehicles, a combination of transports modes, 
behavioural aspects, the design of logistics system, transport planning, choice of partners, an environmental management system and documented emissions and energy data.

\section{N2 New customer interaction}

The second dimension describes the interaction process between the provider and the customer and also the role customers play in the creation of value (den Hertog et al., 2010). However, there are as many different needs as there are customers, and this underlines how important it is for LSPs to know their customers' requirements (Dobie, 2005) and market orientation (Flint et al., 2005) in order to be able to develop new services that better respond to these requirements. Generally, the demand for value-added solutions seems to be weak since many organisations consider such activities too important to outsource, and underestimate LSPs' capabilities in this field (Selviaridis and Spring, 2007). This lack of trust scenario may arise when LSPs start to adapt to environmental concerns and provide new service offerings to the market.

For logistics services in general, there seems to be a mismatch between supply and demand (Murphy and Poist, 2000), and this appears to be repeated when LSPs also try to integrate environmental concerns into their offerings (e.g. Martinsen and Björklund, 2010, Wolf and Seuring, 2010).

\section{N3 New value system/business partners}

The third dimension is the new value system, or the set of actors involved in a co-producing process for a new service in order to create value (den Hertog et al., 2010). Horizontal alliances among LSPs can be seen as a prerequisite for the development of cross-border logistics solutions (Carbone and Stone, 2005). The relationship with other actors can entail increased learning, competence development and adaptation (Halldorsson and Skjoett-Larsen, 2006) and create a positive climate for innovation (Panayides and So, 2005). Hence, to achieve successful and lasting relational exchanges, it could be necessary to go beyond shortterm transactional benefits and incorporate behavioural factors such as trust and commitment into the process (Marasco, 2008).

\section{N4 New Revenue model/pricing}

Far from all new service concepts become successful service innovations, and for those which are successful, the challenge of developing an appropriate revenue model remains. Finding models that distribute costs and revenues appropriately can be especially relevant for services that involve multiple actors (den Hertog et al., 2010). A deficient distribution model is often a reason why new service ideas fail (ibid.).

From the viewpoint of service cost, logistics business processes are very complex (Baykasoglu and Kaplanoglu, 2007). Furthermore, empirical observations indicate that users and providers of logistics services lack the know-how to design suitable agreements and pricing structures (Lukassen and Wallenburg, 2010). Pricing is not only a matter of prices: but is also a matter of designing suitable incentives structures, which are able to govern the further development of the relationship (Kotler and Keller, 2008). When pricing environmental logistics service offerings, LSPs need to catch customers' interest in these offerings on the basis of the value they offer to the customer and on their price (Anderson et al., 2000). Value can be described as what the economic, technical, service and social benefits a customer receives is worth in monetary terms in exchange for the price it pays for a product offering (Anderson and Narus, 1998). 
Should LSPs adopt aggressive penetration-pricing methods to stimulate initial demands for green logistics service offerings or would it instead be better to set a high price in order to maximise short-term revenue and accelerate returns of investments?

Wong et al. (1996) claim that due to the high costs of new product commercialization and the pressure on firms to recoup product-development investment, to use low prices to penetrate or gain increased market shares is not a viable tactic. Generally, raising or lowering the price of an offering does not change the value that the offering has for the customer, but only changes the customer's incentive to purchase (Anderson et al., 2000). Wong et al. (1996) suggest that instead, firms must overcome the technical barriers and achieve price and performance parity with competing traditional offerings.

\section{N5 New service delivery system; organisational, personal and culture}

When a company provides a new service it may require new organizational structures; personal capabilities or team skills. Furthermore, in order to develop and offer innovative services, appropriate management and organization are necessary to allow employees to perform new jobs properly. (den Hertog et al, 2010) For example, benefits generated within LSPs through sustainability initiatives are significantly correlated to a strong managerial attention (Lieb and Lieb, 2010), which can provide employees with the motivation to adopt environmental practices (Lin and Ho, 2008).

Lin and Ho (2008) claim that among LSPs, the intention to adopt green innovations is positively associated with for example, organisational encouragement, the quality of human resources and the accumulation of green-related knowledge. Lambert and Burduroglu (2000) also highlight the role of the sales force. Salespeople must constantly search for new ways to add value for the customer, and this in turn requires knowledge of how to measure and sell the value of logistics, something which should be a part of the training of the sales force.

\section{N6 New service delivery system; technological}

The last dimension concerns technological issues and aims to pinpoint the fact that ICT has enabled numerous service innovations (den Hertog et al, 2010). Recent research has focused on ICT adoption among LSPs (Marasco, 2008), and the ability to utilize ICT has been increasingly considered as one success factor (Langley et al, 2005). Despite the increased importance of ICT for improving performance, there still is a lack of ICT expertise and insufficient financial support for its use among LSPs, especially among small and medium sized firms (Evangelista and Sweeney, 2006). Moreover, offering new management tools and transparency for the logistics services market, for example e-commerce, can have a substantial effect on the interaction between the buyer and the seller of logistics services (Marasco, 2008). ICT is a valuable tool for disseminating and visualizing information, including environmental data, for both internal and external use. Perego et al. (2010) mention specific environmental benefits of ICT adoption, such as air pollution reduction and a decrease in fuel consumption due to optimised and reduced travel distances.

\section{Rationales behind decisions in companies}

As the development of green logistics services is still at such an early stage, it is not yet feasible to measure how the different offerings and offering profiles pay off in terms of return on investments, cost savings or in market shares. Nevertheless, it is of interest to enhance the understanding of why different offerings and offerings patterns can be efficient in economic terms. Hertz and Alfredsson (2003) argue that in order to offer services that deliver customer value, LSPs need to develop their economies of scale/scope advantages, and to develop skills 
and competencies. Starting from this assumption, it becomes interesting to further analyse our research findings with a framework that captures (economic) rationality in decision-making, in a way which is relevant to the studied cases. The different theories of economies of scale/scope are of specific interest in an analysis of this low-margin industry.

Economies of scale are based on a distribution of fixed costs over a higher output, and can be derived from specialization, physical laws and management (Shepherd, 1985). Chandler (1990) explains the phenomenon as the result of a single operating unit increasing its output size (for the same single product) and thereby reducing the unit cost. If the factors that drive economies of scale are pushed too far, diseconomies of scale will arise (Shepherd, 1985). In logistics and distribution, economies of scale have been used to explain for example the rationale behind the global trend of centralising warehousing (e.g. Abrahamsson and Aronsson, 1999). From the perspective of the logistics service industry, specialization is interpreted with regard to the production of services. Hence, a high specialization implies a more narrow service range which can be produced using a smaller number of production resources. With a more diversified resource base, the possible range of offerings also increases.

Chandler (1990) uses the label economies of scope for the phenomenon where the output/input rate increase when a production (or distribution) deals with more than one product, instead of increasing the size for a single product. Thus economies of scope can explain a situation where variation increases, i.e. specialization decreases, and still results in lower costs. Thompson (1967) suggests that another reason for diversification can be overcapacity. Overall, economies of scale and scope result from different technologies, sizes and market locations, which in turn can explain the differences found among cases (ibid.). From a logistics service perspective, different production technologies can be compared with different resource bases for the production of logistics services.

Learning curves relate the efficiencies to time, and describe how the average cost of production declines over time, as the learning process in a company increases its operational efficiency (Shepherd, 1985). Each company and case will show its own specific learning curve. However, it is acknowledged that first-movers (who have acquired knowledge and skills faster than or prior to, their competitors) will have an efficiency advantage over those other companies (Shepherd, 1985; Chandler, 1990).

Efficiency in management and the way in which activities are organised are the key to efficiency (Shepherd, 1985; Thompson, 1967). Administrative activities serve to ensure that the overall business goals are fulfilled through the operational activities (cf Thompson, 1967), and in general, larger facilities reduce the management-related unit cost (Shepherd, 1985). According to Thompson (1967), companies act under uncertainty, which here can be interpreted as the uncertainty of how emerging green concerns will affect their business and market. Seeking rationality under uncertainty means to adapt to such environmental changes (ibid.).

The management of specialized competence relates both to management and specialization efficiencies. Thompson (1967) suggests that the organization of experts into specific departments is related to increased administrative efficiency. Shepherd (1985) discusses the investments related to building competence in a company, which must be weighed against any expected efficiency gains that this could lead to. However, an over-emphasizing on 
management's merits might lead to diseconomies of scale. Shepherd (ibid.) compares this with bureaucracy.

Emerging green demands signify a changing environment for the logistics service industry, and this in turn should trigger organisations to show better results than their competitors (Thompson, 1967). What is less clear, as stated above, is how these "good results" are assessed by the LSPs. This, however, relates directly to the first part of the purpose of this article.

\section{Methodology}

This article is based on a multiple case study. Case research methodology is not only appropriate but is also essential where there is a lack of theory or where the environmental theory does not correspond to that described in the theory (Stuart et al., 2002). Meredith (1998) also highlights that case studies can help to develop understanding, especially in a field where the subject matter is very complex. Both the novelty and the complexity criteria match the situation for LSPs and their offerings in general, as well as their possibility of green offerings.

\section{Literature search procedure}

The theoretical framework consists mainly of literature concerning LSPs and 3PL service offerings, green logistics literature, and is also inspired by service innovation literature. The service innovation literature is used to structure and classify the state of knowledge in the field of logistics service offerings connected to green initiatives. As a point of departure, the article by den Hertog et al. (2010), which introduces six different dimensions that shape a new service offering was used. The logistics service literature in this article has been structured around these dimensions in order to reflect LSPs' new service offerings' especially from a green perspective. The literature review applied a snowball inspired approach, starting in literature known from previous research. This method was chosen since the research area is still in the early stages of development, and early research results connected to green initiatives are not fully represented in the published articles available. Earlier attempts to make more traditional and structured literature searches, as is recommended for example by Tranfield et al. (2003) have proven less successful in identifying relevant literature. Green concerns in service offerings have recently been given some attention in academic literature (Kassinis and Soteriou, 2003) and the existing literature on 3PL services is mainly from a purchasing perspective, and does not give any deeper considerations to green issues (Wolf and Seuring, 2010), and thus is seldom from an LSP's perspective.

Furthermore, due to the early phase in which the problem we describe here finds itself, the literature body has been supported by concepts like economies of scale and scope, and work on organisations and their behaviour in order to investigate the case companies' assumptions of rationality in their move towards increased efficiency and effectiveness.

\section{Empirical data collection}

In the original sample of case companies, about ten potential LSPs actors were identified. Six of these showed interest, and were therefore selected to participate in this study. In order to predict similar results or predict contrasting results for anticipatable reasons, Yin (2009) advocates conducting 6 to 10 case studies. The selection of cases is an important step of building theory from case studies, and the selection of appropriate cases can facilitate the 
controlling of extraneous variation and also help define limits for generalizing the findings (Eisenhardt, 1989). The companies in this study were selected based on the following criteria;

- They had started to adopt green initiatives, and had achieved certain external recognition for this;

- They are on the same market, facing a similar environment with regards to market demands as well as to the rules and legislation for transport related to green issues. The Swedish market was selected due to the researchers' familiarity with this market and ease of access to the case companies.

- The companies vary in size, profile and geographical coverage, and also provide a variety of logistics service offerings.

The selection process identified 2 medium size LSPs with local/regional business and a wide range of transport and basic logistics services; two small/medium size LSPs specialized in express deliveries; and finally two large international LSPs with a wide range of service offerings.

The case descriptions rely mainly on semi-structured focused interviews based on a case study protocol. Semi-structured interviews are suitable for explorative studies as they allow some flexibility regarding level of detail and focus (Yin, 2009), and a case study protocol ensures research reliability, specifically in a multiple case study (ibid.). The interviews were divided into three parts, covering i) a general picture of the company and the range of services offered, ii) factors affecting the company's green initiatives and existence of green logistics service offerings, and iii) how environmental issues can be integrated into the pricing of these service offerings.

The interview structure was sent to each respondent in advance and suggested as an outline for the interview. This was done in order to give respondents an opportunity to reflect upon and search for answers to matters about which they did not have much knowledge. All of the respondents had sufficient knowledge of their company's green initiatives and were either environmental managers or in some way involved in/responsible for the environmental work at their company. The six respondents were interviewed by telephone, each interview lasting for more than one hour. All interviews were recorded and transcribed. Stuart et al. (2002) highlight the importance of reflecting on the transcription of the interview. This was done by giving the respondents the opportunity to reflect and comment on the transcriptions; something which 3 of the respondents did. Besides the interviews, annual reports, website information and internal document were also used to capture sufficient case descriptions.

\section{Data analysis}

The unit of analysis is the logistics service offering and how it is affected by a case company's green initiatives, both today and in a longer time perspective. For this type of explorative research, an abductive approach is recommended (Kovács and Spens, 2005; Rafaeli and Sutton, 1991). Therefore, the research approach in this article has been inspired by an iterative process of travelling back and forth between collected data and relevant and emerging literature to identify patterns and factors affecting the different dimensions. Furthermore, Yin (2009) suggests different strategies for multiple case analyses, for example pattern-matching logic, which compares an empirically based pattern with a predicted one. In this article, the analytic technique known as explanation building has influenced the analysis. This technique is a special type of pattern matching, and is a procedure which is mainly relevant for exploratory studies (Yin, 2009). The goal is to start building an explanation about the cases and to develop ideas for further study, rather than conclude a study. In this article, 
the iterative approach and the pattern-matching logic provided a base for an analysis in two steps;

- an analysis of the service dimensions per se, describing green service offerings and identifying factors affecting these among the case companies; and

- cross-case analysis of each of the six cases, resulting in the identification of empirical patterns across the service dimensions and suggested explanations for these patterns through theoretical pattern-matching.

Each step of the analysis is based on the empirical findings which are then compared to the literature. The analysis presented in the paper only concerns empirical data that has been considered relevant to this article, although the original empirical material is richer and wider. The patterns identified were based on the fact that some characteristics differ from case to case, and that these characteristics can be combined in a way that distinguishes groups of case companies from each other. When patterns were identified, plausible explanations could be derived that provide a basis for further research.

\section{Descriptions of the case companies}

This section describes the LSPs included in the study and is based on general information about the companies and their service offerings, both green and otherwise. For general information of the case companies, see Table 1.

Table 1: General information of the case companies on the Swedish market

\begin{tabular}{|l|l|l|l|l|l|l|}
\hline & Alfa & Beta & Gamma & Delta & Epsilon & Zeta \\
\hline $\begin{array}{l}\text { Geographical } \\
\text { distribution }\end{array}$ & Local/ regional & Regional & National & National & International & International \\
\hline $\begin{array}{l}\text { Approximate } \\
\text { turnover (2009) }\end{array}$ & 61,6 millions $€$ & 124,8 millions $€$ & 28,8 millions $€$ & 50,7 millions $€$ & 530 millions $€$ & 1360 millions $€$ \\
\hline $\begin{array}{l}\text { Number of } \\
\text { employees }\end{array}$ & 111 & 94 & 85 & 158 & 4500 & 4000 \\
\hline $\begin{array}{l}\text { Service offering } \\
\text { range }\end{array}$ & $\begin{array}{l}\text { Diverse road } \\
\text { transport } \\
\text { services, } \\
\text { including } \\
\text { distribution and } \\
\text { heavy } \\
\text { transportation }\end{array}$ & $\begin{array}{l}\text { Diverse road } \\
\text { transport } \\
\text { services, } \\
\text { including } \\
\text { distribution and } \\
\text { heavy } \\
\text { transportation }\end{array}$ & $\begin{array}{l}\text { Express } \\
\text { deliveries }\end{array}$ & $\begin{array}{l}\text { Express and } \\
\text { delivery } \\
\text { transport } \\
\text { services }\end{array}$ & $\begin{array}{l}\text { Wide range of } \\
\text { transport and } \\
\text { logistics services } \\
\text { with a focus on } \\
\text { air and ocean } \\
\text { freight services. }\end{array}$ & $\begin{array}{l}\text { Wide range of } \\
\text { transport and } \\
\text { logistics } \\
\text { services, } \\
\text { covering all } \\
\text { transport modes }\end{array}$ \\
\hline
\end{tabular}

\section{Alfa}

Alfa is one of the largest transport intermediation companies in Sweden. It has about 140 subcontracted carriers who are also part owners, which results in a business concern of over 500 people. Over $90 \%$ of Alfa's services cover the full range within the transport market, with the exception of refrigerated transport. Added services are offered as a complement to all the transport services depending on demand. The customers consist mainly of industries and municipalities, but Alfa also has some end users.

\section{Beta}

Beta is one of the largest logistics and transport service providers in the northern part of Sweden. It has approximately 260 subcontracted carriers who are also part owners, which results in a total of 1000 employees in the entire concern. Beta handles everything from gravel and industrial goods to sensitive consumer products and temperature-sensitive foods. The operations mainly concern FTLs. Beta cooperates closely with its customers in order to develop complete logistics solutions. 


\section{Gamma}

Gamma is a franchise-based express transportation company with access to 700 vehicles and an extensive air route network. Gamma provides systemised and customer-specific door-todoor express delivery solutions for time critical and high value products within high-tech, automotive spare parts and medical equipment. Packages are transported either by road or air, depending on the destination, size and urgency. The main group of customers are businesses, but express deliveries to private customers occasionally occur.

\section{Delta}

Delta is a specialist in the express and delivery transport area, and is part of a larger Nordic company active in the postal and logistics industry. The range of service offerings includes delivery, distribution, express and home delivery. Delta offers different kinds of transportation modes such as air, road or track. Delta works mostly business-to-business, even though in some cases the company delivers directly to private consumers.

\section{Epsilon}

Epsilon is part of one of the world's leading logistics groups, and offers integrated services and customised solutions to manage and transport mail, goods and information. Epsilon offers the whole spectrum of transportation modes, such as air, road, track and sea. The main customer target group is the metal- and telecom industries.

\section{Zeta}

Zeta is also a part of one of the world's largest logistics companies, and provides land transport within Europe, global ocean- and airfreight and customised logistics solutions. Zeta offers everything from rail transport to parcel transport, and offers logistics services such as warehousing and goods handling. Zeta does not offer courier or mail freight. The inputs for industry and consumer products are roughly equal.

\section{Analysis}

The analysis is presented in two steps. The first step analyses the six dimensions of new service offering development, and relates the case findings mainly to the six-dimensional model by den Hertog et al. (2010). The result is presented in Table 2. The second step presents the empirical patterns which were identified when the different dimensions within the cases were combined. It also provides explanations to the different patterns found in the literature on efficiency in organisations.

\section{Part 1: Comparing the six dimensions across cases}

\section{N1: New service concept or service offering}

None of the LSPs studied stated that they currently offered any specific green logistics service. One explanation could be that most of the case companies view green aspects as an added value to their overall service offerings, in line with Peters et al. (1998) and something which can strengthen and broaden the service offering. The absence of specific green service offerings could also be explained by the more general trend in developing logistics service offerings. The service range has increased partly due to the varying and different logistics needs of different kinds of companies (Hertz and Alfredsson, 2003). This is verified by the case companies, which claim that customers' demand for green aspects vary widely, depending for example on the industry in which their customers are active. Beta stated that customers closer to the end consumers, e.g the food industry, have higher and more concrete requirements for green aspects. 
While some LSPs offered separate green choices connected to their general service offerings, others tried to integrate green thinking into the whole company and its service offerings. This is in line with den Hertog et al. (2010). Green choices offered by the LSPs can for example be a combination of transports modes, transport planning and documented emissions data (cf. Martinsen and Huge-Brodin, 2010). Those that stressed the importance of an integration of green thinking mentioned such activities as: continuous sustainability work in their business and with their customers, and brand management to profile the whole company as a greener alternative. Hence, Gamma stated, "I can scarcely believe that we will ever have a green profile" due to a mismatch with its business strategy. The company viewed the integration of green aspects rather as a way to raise the factor "value for money".

Based on the case findings, the LSPs are characterized as either offering green choices or full integration of green thinking in the company and its service offering.

\section{N2: New customer interaction}

The interaction with customers varies among the LSPs studied, even for the regular services. To some extent this is reflected in how they interact regarding green aspects. Several LSPs mentioned a strong desire to work more closely with their customers. As Beta stated "We want to have close cooperation with our customers, be enthusiastic, creative and solutionoriented and try new approaches and methods". This is assumed to lead to a stronger cooperation which will facilitate a more trustful relationship with customers. However, one case company in particular, Epsilon, mentioned that reaching a trustful relationship with its customers poses a problem, as customers are perceived to be somewhat sceptical to new services offered by LSPs (this is in line with Selviaridis and Spring, 2007). Furthermore, a broad range of requirements (some more realistic than others) is also common among customers, even though most of the LSPs studied experience more realistic requirements today.

Some LSPs mentioned a perceived difference in the requirements from customers from different industries. For example, customers from the industry sector are considered less demanding than customers from the food industry. As a result, some LSPs have chosen to address specific segments, while others offer their greener services to the whole customer base. This would require a better understanding and knowledge of customer requirements (Dobie, 2005; Flint et al, 2005). Zeta for example, mentioned that they tried to target customers that are interested in green service offerings, especially those within the automotive industry and also the food industry.

The LSPs are categorised according to whether they interact with all customers - the market in general - or with a specific customer segment with special interests, with regard to green aspects.

\section{N3: New value system/business partners}

With respect to green logistics, many of the case companies viewed their competitors as coplayers rather than as enemies. All of them have some interaction or awareness of their competitors' situation regarding green aspects. While some highlight networking with other companies and organisations as a valuable source for input and ideas (cf Halldorsson and Skjoett-Larsen, 2006; Panayides and So, 2005), others just want to have an overall picture of the competitors' situation. Some case companies do not experience any competition from their competitors, or perceive themselves to be far ahead in green development and hence, 
horizontal cooperation among LSPs on green issues seems less threatening than other horizontal initiatives (cf. Carbone and Stone, 2005).

The categorisation of how the LSPs cooperate with system/business partners is based on networking with competitors as well as others (authorities and research institutions, specifically mentioned) versus being aware of the surrounding competition.

\section{N4: New revenue model/pricing}

The LSPs agree that customers are unwilling to pay extra for green solutions and believe that this situation is unlikely to change in the near future. Generally, there are few signs that price models take green aspects into account. The reasons for this could be explained by a statement from Alfa: "The problem is there are very few customers who value and put sustainability at a high enough level for you to even figure out a special price for these kinds of service offerings". This is in line with Wong et al. (1996). However, the pricing of carbon reports varied: some companies wanted to charge extra while others wanted to include these to add value to the standard offering. Some case companies also mentioned that investments in green development are often more expensive, which raised the question of how to allocate the cost between the LSP and its customer (cf den Hertog et al., 2010). In a situation which is already complex regarding costs and prices (Lukassen and Wallenburg, 2010), adding more complexity and confusion by introducing green aspects seems to be a challenging task for the LSPs.

Another finding concerned the incentives and motives to investment into green aspects. While some LSPs see the costs of green investments as a way to improve market shares through increased value (see Anderson et al., 2000), others are careful to keep track of the competitors' pricing in order to remain level with the market prices.

The LSPs are categorised by the existence of price models and motives to invest in green issues.

N5: New service delivery system; organisational, personal and culture

For all the case companies, difficulties to integrate environmental issues and green thinking into the daily work are a significant barrier. Another problem is to gain a high level of commitment among all their employees. In the literature, organisational encouragement and the quality of human resources are highlighted as positive influences when green innovations are adopted among LSPs (Lin and Ho, 2008). Employee involvement when the company adopts green initiatives seems to be a significant factor. For example, Beta stated; "We want to educate our employees so they can support our customers and everyone in the organisation should know where we are standing when it comes to sustainability issues". However, the view of the role of employees differs, and their role as co-creators of green value is stressed in some cases more than in others. An enthusiastic and committed board was also identified as a positive influence for convincing employees and implementing changes. Therefore, among the case companies, two different drivers to enforce green initiatives in the company have been distinguished, namely; employees in general (bottom-up) or management and board involvement (top-down).

Another interesting finding that distinguished the case companies from each other was how to organise the internal environmental work. Some work more broadly and create a common awareness within the company (broad penetration), while others see different roles among their different departments (functional specialisation). 
This dimension is categorised by two factors; whether the LSPs apply bottom-up versus topdown management of green aspects, and how they organise their resources in terms of broad penetration versus functional specialization.

\section{N6: New service delivery system; technological}

Regarding the development and improvement of vehicle technology, an overall impression given by the case companies is that they strive towards the most environmental friendly technology, acquired at a pace that their economy allows. A renewal of the vehicle fleet will lead to an improvement of the fleet's green/environmental performance. However, there were more differences among the case companies regarding ICT (Information and Communication Technology). Lack of ICT expertise and lack of financial support, especially among small and medium sized firms, was mentioned as a problem by Evangelista and Sweeney (2006) despite the potential for ICT to improve performance. All the case companies have systems in place that to some extent support their environmental needs. However, their ambitions for the near future seem to differ slightly; while some want to develop quite fast to meet increasing customer requirements, others progress more slowly, and some take a wait-and-see approach. Fast progress involves a broad approach with development within different areas and a stable/high investment rate. The case companies with slower progress do improve, but at a slower pace and when it is necessary to do so. In the case companies with a more wait-andsee approach, no specific action was taken or further investment mentioned.

This dimension concerns adoption and development of technology, with a focus on ICT and the LSPs are categorised as fast, slow or wait-and-see.

\section{Part 2: Cross case analysis}

The analysis of the case results which are summarized in Table 2, suggests that there are three different patterns. These are introduced and discussed below. The patterns are based on the fact that some of the characteristics differ from case to case, and that the characteristics can be combined in ways that distinguish groups of case companies from each other. Noticeably, the patterns developed should be viewed independently from each other, despite a slight overlap, and the authors do not intend to create a meta pattern between the different patterns. Instead the patterns developed aim to explore and show different ways to illustrate the underlying rationale and efficiency of LSPs in developing green service offerings.

Table 2: Summary of the most evident case characteristics identified according to the 6 different dimensions of new service offering development.

\begin{tabular}{|c|c|c|c|c|c|c|}
\hline & Alfa & Beta & Gamma & Delta & Epsilon & Zeta \\
\hline $\begin{array}{l}\text { N1: New service } \\
\text { concept or offering }\end{array}$ & Green choice & $\begin{array}{l}\text { Integration / green } \\
\text { choice }\end{array}$ & Full integration & Full integration & $\begin{array}{l}\text { Integration / } \\
\text { green choice }\end{array}$ & Integration \\
\hline $\begin{array}{l}\text { N2: New customer } \\
\text { interaction }\end{array}$ & $\begin{array}{l}\text { Wide range of } \\
\text { customers }\end{array}$ & $\begin{array}{l}\text { Focused customer } \\
\text { segments }\end{array}$ & $\begin{array}{l}\text { Wide range of } \\
\text { customers }\end{array}$ & $\begin{array}{l}\text { Focused } \\
\text { segments }\end{array}$ & $\begin{array}{l}\text { Wide range of } \\
\text { customers }\end{array}$ & $\begin{array}{l}\text { Focused } \\
\text { segments. }\end{array}$ \\
\hline $\begin{array}{l}\text { N3: New value } \\
\text { system / business } \\
\text { partners }\end{array}$ & $\begin{array}{l}\text { Networking } \\
\text { with } \\
\text { competitors }\end{array}$ & $\begin{array}{l}\text { Networking with } \\
\text { competitors and } \\
\text { authorities }\end{array}$ & $\begin{array}{l}\text { Competitor } \\
\text { awareness }\end{array}$ & $\begin{array}{l}\text { Competitor } \\
\text { awareness }\end{array}$ & $\begin{array}{l}\text { Networking } \\
\text { with research } \\
\text { and in general } \\
\end{array}$ & $\begin{array}{l}\text { Competitor } \\
\text { awareness }\end{array}$ \\
\hline $\begin{array}{l}\text { N4: New revenue } \\
\text { model / pricing }\end{array}$ & $\begin{array}{l}\text { New market } \\
\text { shares. } \\
\text { No price } \\
\text { models. }\end{array}$ & $\begin{array}{l}\text { New market share } \\
\text { /added value. } \\
\text { Price raise for } \\
\text { non-partners... }\end{array}$ & $\begin{array}{l}\text { New market } \\
\text { share. } \\
\text { No price models } \\
\text { (strategic. } \\
\text { decision) }\end{array}$ & $\begin{array}{l}\text { New market } \\
\text { shares. } \\
\text { No price models } \\
\text { (strategic. } \\
\text { decision) }\end{array}$ & $\begin{array}{l}\text { Competitive } \\
\text { pricing to } \\
\text { cover green } \\
\text { investments. }\end{array}$ & $\begin{array}{l}\text { Competitive } \\
\text { pricing; } \\
\text { No price models } \\
\text { (strategic. } \\
\text { decision). }\end{array}$ \\
\hline $\begin{array}{l}\text { N5: New service } \\
\text { delivery system; } \\
\text { organisation, } \\
\text { personnel, culture }\end{array}$ & $\begin{array}{l}\text { Top-down. } \\
\text { Specialised. }\end{array}$ & $\begin{array}{l}\text { Bottom-up. } \\
\text { Broad } \\
\text { engagement. }\end{array}$ & $\begin{array}{l}\text { Bottom-up. } \\
\text { Specialised. }\end{array}$ & $\begin{array}{l}\text { Top-down. } \\
\text { Broad } \\
\text { engagement. }\end{array}$ & $\begin{array}{l}\text { Top-down + } \\
\text { bottom-up. } \\
\text { Specialised. }\end{array}$ & $\begin{array}{l}\text { Top-down. } \\
\text { Specialised. }\end{array}$ \\
\hline $\begin{array}{l}\text { N6: New service } \\
\text { delivery system; } \\
\text { technological }\end{array}$ & Wait-and-see. & Fast development. & $\begin{array}{l}\text { Slow } \\
\text { development. }\end{array}$ & Wait-and-see. & $\begin{array}{l}\text { Fast } \\
\text { development. }\end{array}$ & Wait-and-see. \\
\hline
\end{tabular}


The first pattern concerns the relations between the dimensions New service concept/offering (N1) and New value system/business partners (N3), and is partly supported by the New revenue model/pricing dimension (N4).

In the first group - Focus \& abide - the LSPs Gamma, Delta and Zeta all

- treat the green aspects that they offer as fully integrated in the general service offering;

- monitor their competitors, in order not to fall behind; and

- have taken the strategic decision not to introduce specifically priced green services.

The inclusion of green aspects in the general service offering has different levels of ambition and is of a different nature among the three LSPs. Both Gamma and Delta are specialised logistics providers (express services), so it is natural for them to keep to a single type of service offering. Therefore, a diversification of the offering would be out of character with their current business. In addition, the nature of their business - express deliveries - is meant to be fast and reliable rather than aimed to gain customers on the basis of environmental arguments.

Specialisation is one way of increasing efficiency through economies of scale (Shepherd, 1985), which could explain the choice to integrate green aspects throughout the business rather than to single out specific new services. Thompson (1967) suggests that over-capacity is one reason for companies to diversify their business. So if specialisation occurs, it is reasonable to assume that the decision among the LSPs in this group not to diversify is due to a lack of resources for doing so. This might be a way to understand the way case company Zeta reasons - since there is a strategic decision not to single out green offerings, and thus pricing such activities will not attract any internal resources. Further, Thompson (1967) suggests that when organisations are exposed to external change, they are keen to show good results vis-à-vis their competitors. This supports the efficiency of monitoring competitors.

In the second group - Network and explore - the LSPs Alfa, Beta and Epsilon all

- to some degree offer their customers a green choice or option

- promote networking activities regarding green logistics with competitors, academia and other stakeholders

- two of them - Beta and Epsilon - have some ideas about pricing green services differently to their ordinary services.

The LSPs in this group explore the green logistics market through networking and through trials with green offerings, and apply to some extent green price models. Two of them, Alfa and Beta, act on regional markets, providing the large 3PLs with a wide variety of transports. Their already wide variety of service offerings can explain their willingness to introduce yet another type of offering, as in their case, the range of offerings is only incrementally enlarged, and there is a readiness to accommodate different services as well as different prices. This is different from the two express delivery companies, Gamma and Delta that choose to restrict their offering range.

This way of approaching the green aspects can be understood through specialisation; adding green aspects as special offers only increases variety and complexity incrementally, hence the degree of specialisation (Shepherd, 1985) is more or less unaffected, and diseconomies of scope are not a risk. Another explanation to this pattern can be found by considering 
economies of scope (Chandler, 1990). Through a range of services offered, the LSPs studied find the potential gain in introducing green offerings to be higher than the marginal costs they cause, because the "new" services are mainly built on already existing services, knowledge and internal structures.

The explorative attitude towards green offerings in this second group is also confirmed by their willingness to network with all types of stakeholders, including competitors, in order to learn more about this emerging area. In contrast, the "focus \& abide" group appears to be more passive, and feel how the market is developing through monitoring of the competitors.

Shepherd (1985) mentions learning costs and learning curves, and these can help us to understand why the exploring and networking group can be efficient. Through searching for and building knowledge, this group can expect to be better prepared and better informed than their competitors once the green aspects become more important on the market. Their learning curves for developing and adopting new concepts would be steeper than those of the market in general, and thus offer a "first mover" advantage (Chandler, 1990).

In addition, it could also be easier to monitor the market for a focused segment (Gamma, Delta). While networking can prove to be efficient if the range of options is wide, more structured and distant analyses would demand a vast amount of resources.

The patterns identified here are more easily explained for the first four LSPs, and it appears strange that Epsilon and Zeta show different patterns. Their businesses are very similar, and they both represent even wider service offerings than Alfa and Beta. In this sense, it is logical that Epsilon fits the pattern of network and explore. One explanation can be that Zeta has a more top-down management than Epsilon regarding the organisation and management of green aspect. Epsilon is pursuing a number of pilot projects and investigations which are driven locally and based on a will to participate among local divisions. Thus, it is likely that the way the green aspects are managed by Zeta is more standardized, and this resembles the more standardised way Gamma and Delta are managed.

Pattern 2: Internal focus for general "spread" vs. broad engagement to target specific customers

The second pattern concerns the relation between the dimensions New customer interaction (N2) and organisational aspects of New service delivery system (N5).

In the first group - internal focus - the LSPs Alfa, Gamma and Epsilon

- address their green offerings to all or a wide range of their customers

- organise their green efforts internally through specialised departments

In the second group - broad engagement - the LSPs Beta and Delta both

- address focused customer segments with their green offerings, and

- spread competence in green issues widely throughout their organisations.

In the first group, which addresses a wide range of customers with support from a specialised department, one possible explanation for this can be that the broad customer range offers the same broad range of needs, and therefore specialised and focused competence is beneficial in order to meet the different customers' various demands. Shepherd (1985) posits management efficiency as one source of economies of scale, as a situation in which the overhead costs are 
lower per unit if a larger organisation is managed. This could then help to explain the rationale of these LSPs behind the decision to focus and concentrate on managing green aspects. Thompson (1967) suggests that if experts are gathered in specific departments, it is for administrative reasons, i.e. a matter that concerns the level of the organisation that supports the operations. This suggests that keeping an expert department would be an efficient way to support the operations and sales with competence in green logistics.

In the second group, which addresses narrower customer segments with green offerings, explanations can be sought outside the internal organisation, i.e. with the customers. As only narrow segments are approached, it would be logical that customers belonging to these are also more aware of green aspects, and hence possess a larger green competence themselves. If this is the case, it is more efficient for the LSPs not to focus on building a strong competence themselves, but instead to maintain a sufficient level of knowledge among many of their employees. Following the claims made by Shepherd (1985), the investment cost of building up a specialised competence in the green area would mean taking this type of knowledge to an excessive level, and thereby become inefficient through diseconomies of scale.

Case company Zeta falls outside any of those patterns as it directs its green efforts towards specific segments but still maintains a specialised department. From a company structure point of view, Zeta should be comparable to Epsilon. They are both large LSPs, which is why gaining efficiency and effectiveness through specialisation would be a logical choice. However, the differences lie in their approach to customers; Zeta approaches focused customer segments while Epsilon approaches a wide range. Once again, the differences in managing green aspects internally might contribute to understanding why Epsilon has a broad approach to their customers as a result of a combination of top-down and bottom-up management.

\section{Pattern 3: Top-controlled passiveness vs. bottom-up exploration of technology}

The third pattern concerns the relations between the two different dimensions of New service delivery systems: Organisation (N5) and the attitude towards technological innovations of New service delivery system: Technological (N6).

In the first group - top-controlled passiveness - the LSPs Alfa, Delta and Zeta share the features of

- top-down management of green aspects; and

- a wait-and-see attitude towards introducing new technologies that can support the greening of logistics.

In the second group - bottom-up exploration - the LSPs Beta, Gamma and Epsilon share the features of

- bottom-up management of green aspects (this is present but is not the only way in Epsilon); and

- some pace of development and adoption of new technologies which supports greening of logistics is identified.

The pattern that emerges suggests that a bottom-up management of green aspects supports the adoption of technology-based support, while top-management of green aspects hinders the development. Based on economies of scale, two different explanations for this can be mentioned. First, the suggestion that top-controlled passiveness is the more efficient of the 
patterns implies that management efficiency is at work (Shepherd, 1985). This system controls resources and as a result of thorough analysis prevents over-expenditure. Second, suggesting that the bottom-up exploration is the more efficient management style relies again on the costs for learning and learning curves; by allowing local decisions regarding technology adoption, the organisation will learn a lot about good and not-so-good ways of adopting technology for green logistics. The costs for adoption are seen rather as investments for a future where green has a more substantial market value.

Assuming that the explanation lies in economies of scope (Chandler, 1990), and that the adoption of technologies benefits from more bottom-up management, one could suspect that identifying and finding new solutions and determining their value occurs in proximity to customers and operational activities. Thus, if the ability to identify technological options become more scarce the higher up the hierarchy one comes, this could depend on i) the higher the hierarchical level, the less the familiarity with operative activities; or ii) the higher up the hierarchical level, the less obvious the technical competence. The latter explanation clearly calls for more engineers in management.

\section{Conclusions}

The analysis presents a broad picture of the current status of green logistics offerings, and shows how context and strategies to address green development of the company and its service offerings differ among the studied LSPs. The development of green logistics offerings is in an early phase, and although some LSPs have progressed in this field more than others, there is an overall tentativeness concerning the future green process. All the LSPs worked with green issues but in different dimensions, which confirmed the suitability of the original selection of cases. However, variation among the cases was high, and no unanimous picture could be identified in any of the six dimensions investigated.

Despite its early phase, the authors could still discern three different patterns of greening that reflected the current behaviour and the anticipations among the LSPs, namely:

- Focus and abide versus network and explore. This pattern focuses on the strategic standpoint of the greening of the LSPs' activities and the competitive awareness of the development in the logistics market.

- Internal focus for general "spread" versus broad engagement to target specific customers. This pattern, involves customer orientation and the transferring and sharing of green knowledge and competences.

- Top-controlled passiveness versus bottom-up exploration of technology. The last pattern concerns how green activities are managed and controlled within the company and includes the investment of resources.

The different patterns can be explained by how the companies are striving for increased efficiency even though they have chosen sometimes contradicting ways of acting and reasoning. First, among the cases studied this could be partly explained by the differing nature of the LSPs' businesses, where specialisation and diversification appear to be a watershed. Second, this observation could also be seen as one effect of the early stage of development of green logistics in practice. It would then be logical that such different patterns appear, which is in line with how den Hertog et al. (2010) describe the development of a new service offering: different companies choose to focus on different dimensions and in different combinations. 


\section{Further research}

This article is based on a multiple case study and the results can be seen as tentative. To test the results obtained in this investigation, it is necessary to widen the sample and, for example, conduct a questionnaire survey to cover more cases. This would enable a further generalisation, and also a better understanding of how different aspects influence the development of green logistics offerings, for example the type of LSP (range of service offering), company size, type of customer base and geographical coverage.

In addition, and connected to previous research by the authors (e.g. Evangelista et al., 2011) there seems to be a tendency that LSPs operating in the Scandinavian countries are perceived to have an established level of maturity in and sensitivity towards environmental issues. Therefore, the results from this article can inspire LSPs that are less developed with regard to these issues and which are operating in other countries. Furthermore, investigating green logistics offerings in different countries and on different markets would add important dimensions to the understanding of green logistics offerings, especially since logistics is becoming more and more globalized (Peters et al., 1998).

Lin and Ho (2008) stress the need to determine which factors will potentially influence the adoption of green innovations in service sectors. The study presented here offers some tentative explanations based on the concepts of efficiency and effectiveness. However, there are numerous ways of expanding these results through further research. Investigating barriers and drivers (see e.g. Walker et al., 2008) for developing green logistics offerings among LSPs is one way to enhance this understanding. It is known that numerous stakeholders influence the greening of e.g. manufacturing and trading firms (e.g. Carter and Jennings, 2004), but the nature of different stakeholders' influence on green logistics is still to be explored.

The discussions of the patterns identified rely on the concepts of economies of scale and scope and on rationales for organisational decision-making, all of which can offer meaningful ways of understanding the patterns. If other concepts were applied, other explanations would be likely to improve understanding. Literature on company strategy might contribute to explain the rationale behind the strategic decisions taken by the LSPs, and literature from different streams of social networks could support the understanding of why certain LSPs choose to interact and exchange green logistics and green market knowledge. In addition, a resource perspective might provide understanding of how the resource base of the different types of LSPs could explain the different patterns of action that emerge.

As the empirical material shows a picture of an emerging area still in its starting blocks, it would be very interesting to further investigate how actions taken, once taken, actually pay off. The pay-off could be assessed in multiple ways, e.g. in monetary terms as revenues; in marketing terms as markets shares taken or lost; in cost terms regarding running costs and investments; and in environmental terms in the form of carbon efficiency. There are models that depict what should be assessed and managed in greening logistics systems (e.g. McKinnon, 2010), and assessing the decisions and actions taken by applying such models would be very useful, both for researchers and for practitioners. 


\section{References}

Abrahamsson, M. and Aronsson, H. (1999), "Measuring logistics structure", International Journal of Logistics: Research and Application, Vol. 2 No. 3, pp. 263-84.

Andersson, D. (1997), Third party logistics - outsourcing logistics in partnerships. Dissertations No. 34, Linköping Studies in Management and Economics, Linköping University.

Anderson, J.C. and Naurus, J.A. (1998), "Understand what customers value", Harvard Business Review, Vol 76, No. 6, pp. 53-65.

Anderson, J.C., Thomson, J.B.L. and Wynstra, F. (2000), "Combining value and price to make purchase decisions in business markets", International Journal of Research in Marketing, Vol. 17, No. 4, pp. 307-329.

Baykasoglu, A. and Kaplanoglu, V. (2007), "A service-costing framework for logistics companies and a case study", Management Research News, Vol. 30, No. 9, pp. 621-633.

Bask, A.H., Tinnilä, M. and Rajahonka, M. (2010), "Matching services strategies, business models and modular business processes", Business Process Management Journal, Vol. 16, No. 1, pp. 153-180.

Berglund, M. (2000) Strategic Positioning of the Emerging Third-Party Logistics Providers. Dissertations No. 45. Linköping Studies in Management and Economics, Linköping University.

Berglund, M., van Laarhoven, P., Sharman, G. and Wandel, S. (1999), "Third-Party Logistics: Is There a Future?", The International Journal of Logistics Management, Vol. 10, No. 1, pp. 59-70.

Berns, M., Townend, A., Khayat, Z., Balagopal, B., Reeves, M., Hopkins, M. and Kruschwitz, N. (2009), "Sustainability and Competitive Advantage", MIT Sloan Management Review, Vol. 51, No. 1, pp. 18-27.

$\mathrm{B} \varnothing$, E. and Hammervoll, T. (2010) "Cost-based pricing of transportation services in a wholesaler-carrier relationship: an MS Excel spreadsheet decision tool", International Journal of Logistics: Research and Applications, Vol. 13, No. 3, pp. 197-210.

Carbone, V. and Stone, M.A. (2005), "Growth and relational strategies used by the European logistics service providers: rationale and outcomes", Transportation Research: Part E, Vol. 41, No. 6, pp. 495-510.

Carter, C.R. and Jennings, M.M. (2004), "The Role of Purchasing in Corporate Social Responsibility: A Structural Equation Analysis", Journal of Business Logistics, Vol. 25, No. 1, pp. 145-186.

Chandler, A. (1990), Scale and Scope. The Dynamics of Industrial Capitalism, Cambridge, Mass.: Belknap Press.

DB Schenker (2011) Taking responsibility. Providing Solutions, Environmental Brochure 2011, Deutche Bahn AG,

Dobie, K. (2005), "The Core Shipper Concept: A Proactive Strategy for Motor Freight Carriers", Transportation Journal, Vol. 44, No. 2, pp. 37-53.

Eisenhardt, K. (1989), "Building Theories from Case Study Research", Academy of Management Review, Vol. 14, No. 4, pp. 532-550. 
Erhardt, C.E. (2010), Delivering tomorrow. Towards Sustainable Logistics, Deutsche Post, Bonn, Germany.

Evangelista, P., Huge-Brodin, M., Isaksson, K. and Sweeney, E. (2011), "The impact of 3PL's green initiatives on the purchasing of transport and logistics services: an exploratory study", in proceedings of the $20^{\text {th }}$ Annual IPSERA Conference "Vision 20/20 - Preparing today for tomorrow's challenges", $10^{\text {th }}-13^{\text {th }}$ April, Maastricht, The Netherlands.

Evangelista, P. and Sweeney, E. (2006), "Technology usage in the supply chain: the case of small 3PLs", International Journal of Logistics Management, Vol. 17, No. 1, pp. 55-74.

Flint, D.J., Larsson, E., Gammelgaard, B. and Mentzer, J.T. (2005), "Logistics Innovation: A Customer Value-Oriented Social Process”, Journal of Business Logistics, Vol. 26, No. 1, pp. 113-147.

Halldorsson A, and Skjoett-Larsen, T. (2006), "Dynamics of relationship governance in TPL arrangements - a dyadic perspective", International Journal of Physical Distribution and Logistics Management, Vol. 36, No. 7, pp. 490-506.

den Hertog, P., van der Aa, W. and de Jong, M.W. (2010), “Capabilities for managing service innovation: towards a conceptual framework", Journal of Service Management, Vol. 12, No. 4, pp. $490-514$.

Hertz, S. and Alfredsson, M. (2003), "Strategic development of third part logistics providers", Industrial Marketing Management, Vol. 32, No. 2, pp. 139-149.

Isaksson, K. and Björklund, M. (2010), "Development of sustainable logistics services", in Stentoft Arlbjørn, J., (Ed.), Proceedings of the $22^{\text {nd }}$ NOFOMA conference, NOFOMA, 10-11 June 2010 Kolding, Denmark, pp. 985-1000.

Kassinis, G.I. and Soteriou, A.C. (2003), "Greening the service profit chain: the impact of environmental management practices", Production \& Operations Management, Vol. 12, No. 3, pp. 386-402.

Kotler, P. \& Keller, K.L. (2008), Marketing Management, $13^{\text {th }}$ edition, Prentice Hall, Upper Saddle River, USA

Kovács, G. \& Spens, K.M. (2005), “Abductive reasoning in logistics research”, International Journal of Physical Distribution and Logistics Management, Vol. 35, No. 2, pp. 132-144.

Lambert, D.M. and Burduroglu, R. (2000), "Measuring and Selling the Value of Logistics", The International Journal of Logistics Management, Vol. 11, No. 1, pp. 1-17.

Langley, C.J., van Dort, E., Ang, A. and Sykes, S.R. (2005), 2005 Third-Party Logistics Results and findings of the $10^{\text {th }}$ Annual Study, Georgia Institute of Technology, Atlanta, USA

Lieb, K.J. and Lieb, R.C. (2010), "Environmental sustainability in the third-party logistics (3PL) industry", International Journal of Physical Distribution \& Logistics Management, Vol. 40, No. 7, pp. 524-533.

Lin, C-Y. and Ho, Y-H. (2008), “An empirical study on logistics service providers' intention to adopt green innovations", Journal of Technology Management \& Innovation, Vol. 3, No. 1, pp. 17-26.

Lukassen, P.J.H. and Wallenburg, C-M. (2010), "Pricing Third-Party Logistics Services: Integrating Insights from the Logistics and Industrial Services Literature", Transportation Journal, Vol. 49, No. 2, pp. 24-43. 
Maloni, M.J and Carter, C.R. (2006), "Opportunities for Research in Third-Party Logistics", Transportation Journal, Vol. 45, No. 2, pp.23-38.

Marasco, A. (2008), "Third-party logistics: A literature review", International Journal of Production Economics, Vol. 113, No. 1, pp. 127-147.

Martinsen, U. and Björklund, M. (2010), "Green Logistics Offerings and Demands - Matches and Gaps", in Whiteing, T., (Ed.), Proceedings of the $15^{\text {th }}$ Annual Logistics Research Network Conference, LRN, 8-10 September 2010 Harrogate, UK, pp. 453-461.

Martinsen, U. and Huge-Brodin, M. (2010), "Greening the offerings of logistics service providers", in Stentoft Arlbjørn, J., (Ed.), Proceedings of the $22^{\text {nd }}$ NOFOMA conference, NOFOMA, 10-11 June 2010 Kolding, Denmark, pp. 969-984.

McKinnon, A.C. (2010), Environmental sustainability: a new priority for logistics managers, in McKinnon et al. (eds) Green Logistics. Improving the environmental sustainability of logistics, London: KoganPage, pp. 3-30.

Meredith, J. (1998), "Building operations management theory through case and field research", Journal of Operations Management, Vol. 16, No. 4, pp. 441-454.

Murphy, P.R. and Poist, R.F. (2003), "Green perspectives and practices: a "comparative logistics” study”, Supply Chain Management, Vol. 8, No. 2, pp. 122-131.

Panayides, P.M. and So, M. (2005), "Logistics service provider-client relationships", Transportation Research: Part E, Vol. 41, No. 3, pp. 179-200.

Perego, A., Perotti, S. and Mangiaracina, R., (2010), "ICT for logistics and freight transportation: a literature review and research agenda", International Journal of Physical Distribution \& Logistics Management, Vol. 41, No. 5, pp. 457- 483.

Peters, M.J., Lieb, R.C. and Randall, H.,L. (1998), "The use of third-party logistics services by European industry", Transport Logistics, Vol. 1, No. 3, pp. 167-179.

Potter, A. and Lalwani, C. (2008), "Investigating the impact of demand amplification on freight transport", Transportation Research, Vol. 44, No. 5, pp. 835-846.

Rafaeli, A. and Sutton, R.I. (1991), "Emotional contrast strategies as means of social influence: lessons from criminal interrogators and bill collectors", Academy of Management Journal, Vol. 34, No. 4, pp. 749-775.

Selviaridis, K. and Spring, M. (2007), "Third party logistics: a literature review and research agenda", The International Journal of Logistics Management, Vol. 18, No. 1, pp. 125-150.

Sheffi, Y. (1990), "Third party logistics: present and future prospects", Journal of Business Logistics, Vol. 11, No. 2, pp. 27-39.

Shepherd, W. (1985), The Economics of Industrial Organizations, $2^{\text {nd }}$ edition, Prentice Hall, Englewood Cliffs, NJ.

Skjoett-Larsen, T. (2000), "European logistics beyond 2000", International Journal of Physical Distribution and Logistics Management, Vol. 30, No. 5, pp. 377-387.

Stank, T.P., Goldsby, T.J., (2000), "A framework for transportation decision making in an integrated supply chain". Supply Chain Management: An International Journal, Vol. 5, No. 2, pp. 71-77.

Stuart, I., McCutcheon, D., Handfield, R., McLachlin, R. and Samson, D. (2002), "Effective case research in operations management: a process perspective", Journal of Operations Management, Vol. 20, No. 5, pp. 419-433. 
Thompson, J.D. (1967), Organizations in action: social science bases of administrative theory, New York: McGraw-Hill.

Tranfield, D., Denyer, D. and Smart, P., (2003), "Towards a Methodology for Developing Evidence-Informed Management Knowledge by Means of Systematic Review", British Journal of Management, Vol. 14, No. 3, pp. 207-222.

Walker, H., Di Sisto, L. and McBain, D. (2008), "Drivers and barriers to environmental supply chain management practices: Lessons from the public and private sectors", Journal of Purchasing \& Supply Management, Vol. 14, No. 1, pp. 69-85.

Wolf, C. and Seuring, S. (2010), "Environmental impacts as buying criteria for third party logistical services", International Journal of Physical Distribution \& Logistics Management, Vol. 40, No. 1/2, pp. 84-102.

Wong, V., Turner, W. and Stoneman, P. (1996), "Marketing Strategies and Market Prospects for Environmentally-Friendly Consumer Products", British Journal of Management, Vol. 7, No. 3, pp. 263-281.

Wu, H-J. and Dunn, S.C. (1995), "Environmentally responsible logistics systems", International Journal of Physical Distribution \& Logistics Management, Vol. 25, No. 2, pp. 20-38.

Yin, R. (2009), Case Study Research - Design and Methods, $4^{\text {th }}$ edition, SAGE, Thousand Oaks, USA. 